ISSN: 2639-359X

Volume 1, Issue 2, 2018, PP: 33-37

\title{
Minireview - Benefit of Isoflavone for Geriatrics
}

\section{IGP Suka Aryana, RA Tuty Kuswardhani}

Geriatric Division, Department of Internal Medicine

Faculty of Medicine, Udayana University/ Sanglah Central Public Hospital Denpasar, Bali, Indonesia.

suka_aryana@unud.ac.id

*Corresponding Author: IGP Suka Aryana, Geriatric Division, Department of Internal Medicine, Udayana University, Bali, Indonesia.

\section{Abstract}

Isoflavone is a cheap, easily found diet that possible to be consumed on regular basis. Many epidemiological studies and animal experiments as well as clinical trial studies have proved the beneficial effects of isoflavones. However, no large meta-analysis study available to prove significantly. Isoflavones are believed to have the effect of decreasing the menopausal symptoms, prevent osteoporosis, prevent cardiovascular event, and even prevent breast and prostate cancer. Isoflavones mechanism of action including numerous pathways to reach the effects, but still being a challenge to be investigated further. Isoflavones are expected to replace HRT in the future that have been shown to have a very high risk of malignancy. Further clinical studies in larger scale and also biomolecular research are needed to prove the isoflavones benefit for the elderly population.

\section{INTRODUCTION}

Isoflavone is a plant-derived natural ingredient belonging to phytoestrogens. Isoflavone is now being a potential alternative theraphy for patients with clinical conditions associated with hormonal disorder such as cancer, menopause, cardiovascular disease and osteoporosis. Research data have shown many clinical benefits of isoflavone, especially in animal studies and some clinical studies in human, but clinical studies of both large and long-term studies are needed to prove them..$^{1,2}$

The chemical structure of isoflavone is very similar to mammalian estrogens. Phenolic ring is an important element that will bind to estrogen receptor. Due to the similarity of these structures isoflavone can bind to estrogen receptor (ER). Differences in isoflavon bind to ER will affect the differences of biological activity of isoflavone in individuals. ${ }^{3}$

The effects of in vivo isoflavone are more difficult to predict because of the influence by the pathway into the body, isoflavone metabolism form, bioavailability, half-life, time and exposure levels, intrinsic estrogen and hormonal factors affecting the activity of isoflavone. All of these factors should be considered in designing studies to examinethe effect of isoflavone. The discovery of a second estrogen receptor by Kuiper named "ER $\alpha$ " is different from the previous type. Both $\mathrm{ER} \alpha$ and ER $\beta$ receptors play a role in regulation and activity in the body. $\operatorname{Er} \beta$ receptors are present in the brain, bone, bladder and vascular epithelium in which all of these tissues are very responsive to hormonal theraphy. ${ }^{2-4}$

\section{ISOFLAVONE SOURCES}

Isoflavone mostly found in soybean and other products made from soybean. The substances that are the source of isoflavone are nuts. Isoflavone mainly formed due to glucosidation process in plants that is water soluble. The content of isoflavone in various types of food with soybean raw materials of about $0,1-0,3 \mathrm{mg} / \mathrm{g}$. Some suplement products with concentrate extract from soybean are widely produced. But the clinical effects of isoflavone suplements have not fully evaluated. Megadoses usage of isoflavone is still being a corncern because of the side effects that possibly happen that occur as well as the use of other suplements. The intake of protein containing isoflavone is sourced from foods such as nuts especially soybeand and soy products (milk, tempeh, tofu). In western countries, isoflavone intake only ranges $1 \mathrm{mg}$ /day where as in Asia such as 
Minireview - Benefit of Isoflavone for Geriatrics

China and Japan that consume a lot of soybeans, soy day. This distinction is more obvious between the products, or in vegetarian ranging from $20-50 \mathrm{mg} /$ urban and rural population..$^{5-7}$

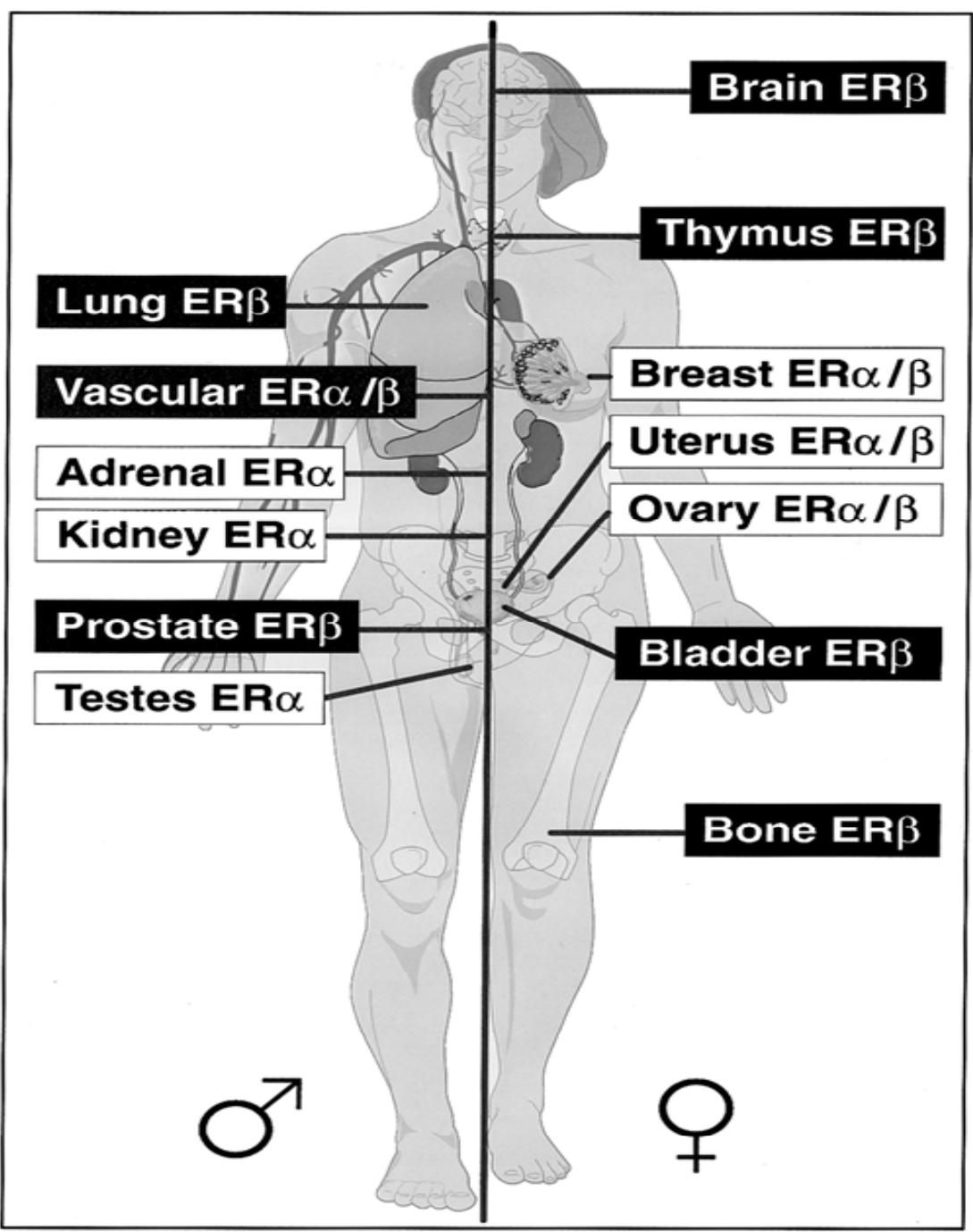

Figure 1. Different receptor location of ER $\alpha$ and ER $\beta$ in male and female ${ }^{3}$

Table 1. Type of food and content of isoflavone and its calories ${ }^{7}$

\begin{tabular}{|l|c|c|c|c|}
\hline \multicolumn{1}{|c|}{ Food } & Serving & Soy protein $(g)$ & Isoflavone content $(\mathrm{mg})$ & Kcal \\
\hline Soy Burger & 1 patty & 8 & 7 & 100 \\
\hline Soy nuts & $1 \mathrm{oz}$ & 12 & 38 & 150 \\
\hline Soy Milk & $1 \mathrm{c}$ & 8 & 24 & 100 \\
\hline Texturized Vegetable Protein (TVP) & $1 / 4 \mathrm{c}$ & 14 & 27 & 50 \\
\hline Tofu & $3 \mathrm{oz}$ & 9 & 33 & 45 \\
\hline Soy Protein Bar & $1 \mathrm{bar}$ & 6 & $10-15$ & 180 \\
\hline Soy Breakfast Patty & $2 \mathrm{patties}$ & 16 & 4 & 160 \\
\hline Soy Flour & $1 / 4 \mathrm{c}$ & 12 & 33 & 90 \\
\hline Soy Beans, Boiled & $1 / 2 \mathrm{c}$ & 7 & 47 & 190 \\
\hline Tempeh & $1 / 2 \mathrm{c}$ & 18 & 36 & 200 \\
\hline Soy Nut Butter & $2 \mathrm{Tbs}$. & 8 & 0 & 160 \\
\hline
\end{tabular}


Minireview - Benefit of Isoflavone for Geriatrics

\section{ABSorption AND Metabolism}

The isoflavone active ingedients is strongly influenced by the bioavailability process of dietary intake, absorption, metabolism, and biological activity after being bound to receptors. In the gastrointestinal tract, the metabolism and bioavailability is strongly influenced by the microflora. Isoflavone of soybeans after being eaten will undergo hydrolysiss process by glucosidase enzyme and produce aglycones, daidzein, genistein and glucitein. This substances will absorb and metabolised specifically to form equol and p-ethylphenol. Metabolism that occur is also strongly affected by diet components. High carbohydrate diet will improve the fermentation process so that more equol produced. Biological activity of equol is higher that its daidzein precursor. The use of radical antibiotics will kill the microflora so that it will lower the isoflavone level drastically. The half-life of daidzein and genistein is about 7,9 hours. Plasma concentration can reach $50-800 \mathrm{ng} / \mathrm{mL}$ when consuming isoflavone around $50 \mathrm{mg} /$ day. Regular consumption to obtain isoflavone levels range from $40-80 \mathrm{pg} / \mathrm{mL}^{6,7}$

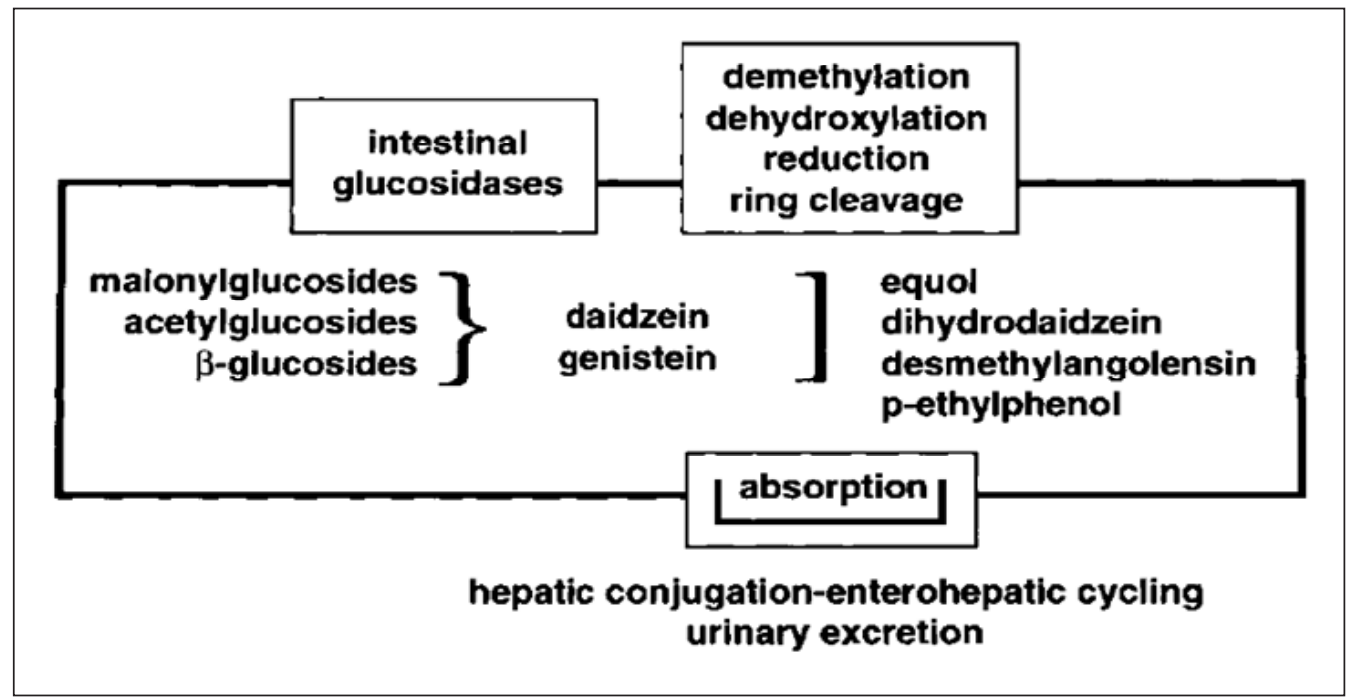

Figure 2. Metabolism process of isoflavone from soy intake in the gastrointestinal tract. ${ }^{7}$

\section{Clinical EFFECTS OF ISOFLAVONE}

Studies on isoflavones are still much needed to clearlyunderstand the pharmacokinetics and dynamics of isoflavones. Optimal doses of isoflavone being studied in premenopausal women, given aglycones $50 \mathrm{mg} /$ day was obtain an hormonal effects compared with $25 \mathrm{mg} /$ day doses. Besides of doses, length of administration is also greatly affect the desired hormonal effects. Epidemiological and clinical trials suggest that estrogen theraphy in the postmenopausal women giving protective effects of the cardiovascular, prevent osteoporosis, improve cognitive function and reduce menopausal symptoms. But, this hormone replacement theraphy (HRT) is increasingthe risk of breast cancer. This prompted researcher to know the protective effect of high isoflavone diet as in the vegetarian group which turned out to be much milder postmenopausal symptoms. Isoflavone potentially became the substitute of HRT as a source of external estrogens that also decrease the incidence of osteoporosis, breast cancer and the other postmenopausal symptoms. ${ }^{8-10}$

The isoflavone mechanism of actions is very diverseand provides many opportunities for further investigation. From various studies that have been done, it can be concluded that isoflavone have mechanism of action including $:{ }^{10}$

1. Bind to estrogen receptors

2. Inhibit the reactive oxygen species (ROS) production

3. Triger the destruction of DNA strand so that apoptosis can perform easily

4. Inhibit the angiogenesis

5. Inhibit the production of thrombin and platelet aggregation

6. Increase the LDL receptor activity 
Based on this mechanism of action, isoflavone will have the desired clinical effects. The interestingthing is isoflavone has estrogenic and antiestrogenic effects. This effect was investigated because of the effect in in vivo studies were different with the in vitro studies. It is suspected that isoflavones will have antiestrogeic effect if estrogen level in the body are still high and will have an estrogenic effect when the estrogen levels are low or in postmenopausal period. This remains a controversy. ${ }^{11}$

\section{EFfECT In MENOPAUSE}

Studies conducted in Europe, Malaysia, and China found the incidence of hotflushes $70-80 \%, 57 \%$ and $18 \%$. After being given a diet with soy content (fitoestrogen/ isoflavone) for 12 weeks found symptoms reduction for $40-55 \%$ while in control decreased for $20-35 \%$. The effect on vaginal epithelium and histological outcome was not significant. This inconsistent results is probably because of the optimum isoflavone intake has not been measured. Measurement of isoflavone levels also shows varying results that indicate the isoflavone metabolism in every sample is very individual. ${ }^{11}$

\section{Cardiovascular EFfect}

Mortality due to cardiovascular disease in men and women is similar and in postmenopausal women more death are attributable to cardiovascular disease. Estrogen deficiency is associated with impaired lipoprotein metabolism resulting in dyslipidemia. The cardioprotective effect on HRT (estrogen) is because of the lipid profile improvements such as decreased LDL cholesterol and increased HDL cholesterol. This directly contribute on vascular wall in the process of atherosclerosis. The mechanism of isoflavone to improve dyslipidemia is multimechanism. Isoflavone can improve the secretion of synthesis and bile excretion that play a role in cholesterol homeostasis in gastrointestinal tracts and its hepatic cycle. Isoflavone also activate the LDL receptor to increase the uptake of cholesterol. Another mechanism is the effect of estrogen can directly improve lipid profile. ${ }^{7-9}$

Isoflavones have an antioxidant effect that can decrease the amout of oxidated LDL so it can act as cardioprotector. Isoflavone can also increase the reactivity of coronary blood vessel thereby causing the coronary vasodilatation resulting in blood flow to heart muscle. Another mechanism on endotel is that genistein can inhibit the coagulation process through inhibition on platelet derived growth factor and thrombin formation. This may also due to genistein effect on inhibiting the tyrosine kinase, which is a central enzime of inflammation process and thrombin formation. ${ }^{9}$

\section{OSTEOPOROSIS}

Ipriflavone is a syntetic form of isoflavone whose estrogen activity is mild but the structure is similar to daidzein and genistein. Giving $600 \mathrm{mg} /$ day of ipriflavone prevents osteoporosis and increase the bone formation. Low doses of genistein can prevent the osteoporosis process but the high doses did not work. Genistein not only affect the tyrosine kinase but also in growth factor and sitokin that plays an important role in osteoclas activity. Isoflavone can prevent the osteoclast formation so that there is no bone destruction and decreasing the calcium excretion in urine and isoflavone also help in the absorption of calcium in gut. ${ }^{10}$

\section{Breast and Prostate Cancer}

There is no differences in the bioavailability or metabolism of isoflavone between women and men. The hypocholesterol effect also found in several studies but Cassidy found that $60 \mathrm{~g} /$ day of isoflavone diet did not get the desired effect either on the cholesterol improvement or platelet aggregation. The anti-cancer effects of isoflavones are based on epidemiological studies in which Asian countries with high isoflavone consumption have a low incidence of breats and prostate cancer compared with countries in Europe and America. Isoflavone inhibit the tyrosine kinase protein that triggers the occurence of cancer cells. ${ }^{9,11}$

\section{CoNCLUSSION}

Isoflavone have many epidemiological studies and animal experiments as well as clinical trial studies have proved the beneficial effects. However, no large meta-analysis study available to prove significantly. Isoflavones are believed to have the effect of decreasing the menopausal symptoms, prevent osteoporosis, prevent cardiovascular event, and even prevent breast and prostate cancer. Mechanism of action isoflavone including numerous pathways, but still being a challenge to be investigated further including in elderly population. 


\section{REFERENCES}

[1] Setchell KD. Phytoestrogens: the biochemistry, physiology, and implications for human health of soy isoflavones. Am J Clin Nutr 1998;68:1333S$46 \mathrm{~S}$.

[2] Cassidy A, Brown JE, Hawdon A, Faughnan MS, King LJ, Millwar J, et al. Factors affecting the bioavailability of soy isoflavones in humans after ingestion of physiologically relevant levels from different soy foods. J Nutr 2006;136:45-51

[3] Lissin LW, Cooke JP. Phytoestrogens and cardiovascular health. J Am Coll Cardiol 2000; 35:403-10.

[4] Adlercreutz H, Mazur W. Phyto-oestrogens and Western diseases. Ann Med 1997;29:95-120.

[5] Adlercreutz H, Markkanen H, Watanabe S. Plasma concentrations of phyto-oestrogens in Japanese men. Lancet 1993;342:1209-10.

[6] Horiuchi T, Onouchi T, Takahashi M, Ito H, Orimo $\mathrm{H}$ : Effect of soy protein on bone metabolism in postmenopausal women. Osteoporosis 2000; 11:

721-724

[7] Setchell KDR and Cassidy A, Dietary Isoflavones: Biological Effects and Relevance to Human HealthJ. Nutr. 1999;129: 758S-767S

[8] Hooper J, Ryder, Kurzer M.S, Lampe J.W., Messina M.J., Phipps W.R, and Cassidy A, Effects of soy protein and isoflavones on circulating hormone concentrations in pre- and post-menopausal women: a systematic review and meta-analysis Human Reproduction Update, Vol.15, No.4 pp. 423-440, 2009

[9] Barnes S, Soy Isoflavones-Phytoestrogens and What Else? J. Nutr. , 2004;134: 1225S-1228S.

[10] Weaver CM and Cheong JMK, Soy Isoflavones and Bone Health: The Relationship Is Still Unclear. J. Nutr. 2005; 135: 1243-1247.

[11] Zhan S and Ho SC, Meta-analysis of the effects of soy protein containing isoflavones on the lipid profile. AmJ Clin Nutr 2005;81:397- 408.

Citation: IGP Suka Aryana, RA Tuty Kuswardhani. Minireview - Benefit of Isoflavone for Geriatrics. Open Journal of Geriatrics. 2018; 1(2): 33-37.

Copyright: (C) 2018 IGP Suka Aryana, RA Tuty Kuswardhani. This is an open access article distributed under the Creative Commons Attribution License, which permits unrestricted use, distribution, and reproduction in any medium, provided the original work is properly cited. 